\title{
SYSTEM LOCK AND CONTROLLING CLASS ROOM DENGAN INTERFACE ANDROID BERBASIS ARDUINO UNO
}

\author{
Endang Sunandar ${ }^{1}$ \\ Khanna Tiara ${ }^{2}$ \\ MohamadDaud ${ }^{3}$ \\ Dosen STMIK Raharja ${ }^{1}$, Alumni STMIK Raharja jurusan Teknik Informatika ${ }^{2}$, Mahasiswa \\ STMIK Raharja ${ }^{3}$ \\ e-mail: endang.sunandar@raharja.info ; khanna.tiara@raharja.info ; daud@raharja.info
}

Diterima : 17 Mei 2015/ Disetujui : 3 Agustus 2015

\begin{abstract}
In day-to-day environment, buildings that have a lot of room doors sometimes appears constraints when should lock and unlock all the room one by one, because the security guards had to lock and unlock the doors on each floor of the building space manually. There are several systems that can be tailored to these problems, one of which is a lock and controlling system with Bluetooth facility. In this system using the Bluetooth facility to give commands to the microcontroller used, the namely ATmega328-based ArduinoUno. Users simply open the Bluetooth Controller application and connect to the bluetooth Android smartphone which is mounted on the door, then enter the password "1234" and press " $A$ " to open, " $b$ " to close, " $c$ " to unlock, " $d$ " key to lock the door, then the officer can control the door electrically.
\end{abstract}

Keywords: Bluetooth, Door Room, ATmega328, ArduinoUno

\begin{abstract}
ABSTRAK
Dalam lingkungan sehari-hari, gedung-gedung yang memiliki banyak pintu ruangan terkadang muncul kendala disaat harus mengunci dan membuka semua ruangan satu persatu, karena petugas keamanan tersebut harus mengunci dan membuka pintu ruangan disetiap lantai gedung secara manual.Ada beberapa sistem yang dapat dirancang dari permasalahan tersebut, salah satunya adalah sistem lock and controlling dengan fasilitas Bluetooth.Dalam sistem ini menggunakan fasilitas Bluetooth untuk memberi perintah pada mikrokontroller yang digunakan, yaitu ATMega328 berbasis ArduinoUno. Pengguna cukup membuka aplikasi Bluetooth Controller dan mengkoneksikan smartphone androidnya ke bluetooth yang sudah terpasang di pintu tersebut, lalu memasukan password "1234" dan menekan tombol " a" untuk membuka, "b" untuk menutup, "c" untuk membuka kunci, "d" untuk mengunci kunci pintu, maka petugas dapat mengendalikan pintu tersebut secara elektrik.
\end{abstract}

Kata kunci: Bluetooth, Pintu Ruangan, ATMega328, ArduinoUno 


\section{PENDAHULUAN}

Perkembangan teknologi yang sangat pesat telah diiringi oleh kemajuan teknologi mikrokontroller saat ini, dan maraknya penggunaan telepon seluler pada semua kalangan.Sehingga segala bidang relatif bisa dipandang sangat relevan berhubungan dengan Mikrokontroller. Teknologi mikrokontroller merupakan solusi yang dapat dimanfaatkan untuk mengatasi biaya, serta menjadi model yang fleksibel. Pesatnya perkembangan mikrokontroller akhir-akhir ini, memicu berkembangnya inovasi baru yang memanfaatkan mikrokontroller sebagai mempermudah pekerjaan manusia.

Dalam lingkungan kehidupan seharihari, gedung - gedung yang memiliki banyak pintu ruangan terkadang muncul kendala disaat harus mengunci dan membuka semua ruangan satu persatu, karena petugas keamanan tersebut harus mengunci dan membuka satu persatu ruangan disetiap lantai gedung secara manual. Hal itu cukup menyulitkan petugas keamanan tersebut.

Dengan melihat hal tersebut yang terjadi di lingkungan kehidupan masyarakat, maka dicari suatu pemecahan dari masalah tersebut. Dalam laporan ini mencoba membahas aspek pendukung dalam upaya memecahkan masalah yang terjadi dilingkungan kehidupan masyarakat umum.

Sementara ini untuk dapat memecahkan masalah tersebut maka dibuatkan sebuah sistem yang menggunakan Smartphone Android yang dapat memberi perintah lewat mikrokontroller berbasis Arduino Uno untuk mengunci dan membuka pintu ruangan. Tujuan dari penelitian ini adalah untuk menerapkan berbagai teori mengenai sistem pengontrolan secara elektrik, dan komunikasi data antara mikrokontroller dengan Smartphone Android. Membuat sistem pintu ruangan kelas yang dikendalikan oleh mikrokontroller berbasis Arduino Uno dan dikontrol dengan aplikasi yang dibuat di Smartphone Android.

\section{LANDASAN TEORI}

\section{- Definisi Bluetooth}

Menurut Dwi Agus Diartono (2009:70) "Bluetooth adalah sebuah teknologi komunikasi wireless (tanpa kabel) yang beroperasi dalam pita frekuensi $2,4 \mathrm{GHz}$ unlicensed ISM (Industrial, Scientific and Medical) dengan menggunakan sebuah frequency hopping tranceiver yang mampu menyediakan layanan komunikasi data dan suara secara realtime antara host-host bluetooth dengan jarak jangkauan layanan yang terbatas ".

\section{- $\quad$ Definisi ATMega328}

Menurut Syahid (2012:33)," ATMega328 merupakan mikrokontroler keluarga AVR 8 bit. Beberapa tipe mikrokontroler yang sama dengan ATMega8 ini antara lain ATMega8535, ATMega16, ATMega32, ATMega328, yang membedakan antara mikrokontroler antara lain adalah, ukuran memori, banyaknya GPIO (pin input/output), peripherial (USART, timer, counter, dll)."

Dari segi ukuran fisik, ATMega328 memiliki ukuran fisik lebih kecil dibandingkan dengan beberapa mikrokontroler diatas. Namun untuk segi memori dan periperial lainnya ATMega328 tidak kalah dengan yang lainnya karena ukuran memori dan periperialnya relatif sama dengan ATMega8535, ATMega32, hanya saja jumlah GPIO lebih sedikit dibandingkan mikrokontroler diatas.

\section{- Definisi Pengontrolan}

Menurut Erino Fiardi (2012:261), "Suatu system control otomatis dalam 
suatu proses kerja berfungsi mengendalikan proses tanpa adanya campur tangan manusia (otomatis)". Kontrol otomatis mempunyai peran penting dalam dunia industri modern saat ini. Seiring perkembangan kemajuan ilmu pengetahuan dan teknologi, sistem kontrol otomatis telah mendorong manusia untuk berusaha mengatasi segala permasalahan yang timbul di sekitarnya dengan cara yang lebih mudah, efisien dan efektif. Adanya kontrol otomatis secara tidak langsung dapat menggantikan peran manusia dalam meringankan segala aktifitasnya.

Berdasarkan Ejaan Yang Disempurnakan (EYD) pengontrolan berasal dari kata kontrol. Kontrol sama dengan pengawasan, pemeriksaan dan pengendalian. Pada industri besar dan modern sangat memerlukan tenaga ahli perencanaan sistem pengendali dan perancangan desain sistem pengendali, termasuk teknisi profesional sebagai operator. Tidak menutup kemungkinan bahwa pengontrolan berasal dari berbagai disiplin ilmu yang saling berhubungan karena teori sistem pengendali modern dikembangkan guna mengatasi kerumitan yang dijumpai pada berbagai system pengendalian yang menuntut kecepatan dan ketelitian yang tinggi dengan hasil output yang optimal.

\section{- Definisi Perangkat Mobile}

Menurut purnama (2010:5), "Perangkat mobile (juga dikenal dengan istilah cellphone, handheld device, handheld computer, "Palmtop", atau secara sederhana disebut dengan handheld) adalah alat penghitung (computing device) yang berukuran saku, ciri khasnya mempunyai layar tampilan (display screen) dengan layar sentuh atau keyboard mini". Untuk mendapatkan pelayanan dan kenyamanan dari sebuah komputer konvensional yang dapat dibawa-bawa dan praktis adalah smartphone dan PDA. Kedua peralatan ini yang paling populer, selain itu ada Enterprise Digital Assistants yang dapat dikembangkan lebih jauh untuk kepentingan bisnis, yang menawarkan peralatan yang mampu me-ngambil data terintegrasi seperti Bar Code, RFID dan Smart Card.

\section{- Definisi Sinyal}

Pengertian Sinyal menurut Mulyanto (2009:65), "Sinyal adalah energi elektrik (arus atau gelombang) dapat menyimpan informasi jika dibuat dalam variasi tertentu dan satuan waktu tertentu pula/intensitas. Variasi energi tersebut diberi istilah sinyal (signal)". Sinyal terbagi dalam 2 bagian yaitu: Sinyal Analog dan Sinyal Digital.

- Sinyal Analog Sinyal analog adalah sinyal data dalam bentuk gelombang yang kontinyu, yang membawa informasi dengan mengubah karakteristik gelombang. Dua parameter/ karakteristik terpenting yang dimiliki oleh isyarat analog adalah amplitude dan frekuensi. Isyarat analog biasanya dinyatakan dengan gelombang sinus, mengingat gelombang sinus merupakan dasar untuk semua bentuk isyarat analog.

- Sinyal Digital Sinyal digital merupakan sinyal data dalam bentuk pulsa yang dapat mengalami perubahan yang tiba-tiba dan mempunyai besaran 0 dan 1 . Teknologi sinyal digital hanya memiliki dua keadaan, yaitu 0 dan 1 , sehingga tidak mudah terpengaruh oleh noise, tetapi transmisi dengan sinyal digital hanya mencapai jarak jangkau pengiriman data yang relatif dekat. Sinyal digital juga biasanya disebut juga sinyal diskret.

\section{- Konsep Dasar Prototipe}

Pengertian Prototipe menurut Simarmata (2010:64)," Prototipe adalah perubahan 
cepat di dalam perancangan dan pembangunan prototype. Menurut Wiyancoko (2010:120),'Prototipe adalah model produk yang mewakili hasil produksi yang sebenarnya". Dari pendapat yang dikemukakan di atas dapat disimpulkan bahwa prototype adalah proses pembuatan model produk dalam perancangan.

\section{LITERATURE REVIEW}

Banyak penelitian yang sebelumnya dilakukan mengenai sistem keamanan pintu dan pengenalan wajah.Dalam upaya pengembangan pengamanan pintu ini perlu dilakukan studi pustaka sebagai salah satu dari penerapan metode penelitian penelitian yang akan dilakukan. Mengidentifikasikan metode yang pernah dilakukan, meneruskan penelitian sebelumnya, serta mengetahui orang lain yang spesialisasi dan area penelitiannya sama dibidang ini. Beberapa Literature review tersebut adalah sebagai berikut:

1. Penelitian yang dilakukan oleh Reza Nusyah Putra (2014) yang berjudul "Prototipe Alat Pembersih Toren Otomatis menggunakan SMS gateway pada PT. Cahaya Televisi Indonesia”. Penelitian ini membahas tentang sistem pengontrolan pembersih Toren air dengan media SMS Gateway untuk memberikan instruksi. Jadi saat pengguna ingin mengoperasikan pembersih toren air cukup mengirim SMS ke nomor yang terpasang di Modem SMS gateway tersebut.

2. Penelitian yang dilakukan oleh Roni Fitramadhana (2013) yang berjudul "Aplikasi Sistem Keamanan Pada Ruangan Server Dilengkapi Sensor Suhu, Mekanik Pintu Dan Pengenalan Kode Akses Didukung Webcam Berbasiskan Client Server". Penelitian ini membahas tentang bagaimana merancang, membuat dan mengimplementasikan komponen komponen sistem yang meliputi pengontrol device ,Sensor photodioda,Sensor Suhu, Client dan Server dengan output pengontrolan Electronic Door Lock, Rotator pintu mekanis,Alarm dan rekaman file dari webcam sebagai pemantauan visual dari ruangan. Kemudian tujuan dan manfaat dari penelitian ini yaitu, bertujuan untuk memanfaatkan perkembangan teknologi untuk diterapkan dalam sistem keamanan ruangan,dengan studi kasus adalah ruangan server. Manfaat yang didapat dari sistem ini adalah dapat meningkatkan keamanan dalam suatu ruangan dan dapat mempermudah pengguna sistem dalam memantau suatu ruangan dari jarak jauh.

3. Penelitian yang dilakukan oleh Imam Sibro Malisi (2013) yang berjudul "Prototype Alat Pengendali Gerbang Menggunakan SMS Gateway". Penelitian ini membahas tentang bagaimana merancang, membuat sistem pengendalian gerbang rumah berbasis SMS Gateway, jadi saat pengguna ingin membuka atau menutup gerbang pintu pengguna cukup mengirim SMS ke nomor yang terpasang di Modem SMS gateway tersebut dan pintu tersebut terbuka secara otomatis.

4. Penelitian yang dilakukan oleh Heri Kuswanto (2014) yang berjudul "Sistem Proteksi Kendaraan Bermotor menggunakan Android Berbasis Mikrokontroller ATMega328”. Penelitian ini membahas tentang bagaimana merancang sistem keamanan pada kendaraan bermotor, dan dapat mengontrol hidup atau matinya mesin kendaraan pengguna tersebut pada handphone Androidnya. Disamping itu alat ini juga menggunakan sensor cahaya yang difungsikan untuk mendeteksi kendaraan ketika dihidupkan. Jadi kendaraan tidak akan takut dicuri karena sudah terproteksi dengan alat ini.

5. Penelitian yang dilakukan oleh Dhida Restu GM (2014) yang berjudul "Prototype Pengendali Pintu dan Jendela Mobil Menggunakan Smartphone 
Berbasis ATMega 328P Di Kelurahan Cibogo". Penelitian ini membahas tentang bagaimana mengendalikan pintu dan jendela mobil hanya dengan smartphone yang sudah terkoneksi dengan bluetooth yang ada pada mikrokontroller. Sinyal yang sudah dikirim lewat bluetooth akan diterima oleh mikrokontroller dan mikrokontroller akan menjalankan motor servo untuk membuka pintu ataupun membuka jendela sesuai keinginan user.

Dari 5 (lima) literature review yang ada, telah banyak penelitian mengenai mikrokontroller yang terhubung bluetooth dan menggunakan media smartphone android . Namun dapat disimpulkan pula bahwa belum ada penelitian yang secara khusus membahas mengenai Pembangunan prototipe system lock and controlling class room dengan interface android berbasis arduino uno di perguruan tinggi raharja. Itulah alasan mengapa penulis tertarik untuk membahas hal tersebut.Agar nanti bisa dijadikan acuan sebagai referensi oleh dosen maupun mahasiswa.

\section{PERMASALAHAN}

Masalah adalah kesenjangan (discrepancy) antara apa yang seharusnya (harapan) dengan apa yang ada dalam kenyataan sekarang. Penelitian diharapkan mampu mengantisipasi kesenjangankesenjangan tersebut.Masalah yang perlu dijawab melalui penelitian cukup banyak dan bervariasi misalnya masalah dalam bidang teknologi.

Rumusan masalah dalam penelitian ini adalah bagaimana pintu ruangan kelas dapat terkunci secara elektrik dan dikendalikan mikrokontroller berbasis Arduino Uno, bagaimana membuat sebuah aplikasi di Smartphone Android yang dapat mengontrol dan mengunci pintu ruangan kelas, bagaimana membuat mikrokontroller mengerjakan tugasnya saat aplikasi di
Smartphone Android mengontrol dan mengunci pintu ruangan kelas tersebut.

Berdasarkan dari rumusan masalah yang dihasilkan maka tujuan yang ingin dihasilkan adalah pintu ruangan kelas sudah dipasang 2 buah motor servo yang terhubung pada arduino uno yang sudah diprogram, yang menjadikan petugas tidak perlu repot untuk membuka, menutup, mengunci pintu dan membuka kunci pintu ruangan secara manual. Sebuah aplikasi yang sudah ada di Play Store dapat diunduh secara gratis bernama Bluetooth Controller.Petugas sukup mengatur aplikasi ini sesuai kebutuhan seperti mengunci, membuka kunci, membuka dan menutup pintu.Dan ketika mikrokontroller yang sudah diprogram tersebut sudah dapat menjalankan tugasnya maka petugas cukup mengkoneksikan bluetooth dismartphone androidnya.

\section{PEMECAHAN MASALAH}

Prosedur sistem yang berjalan sebelumnya untuk membuka pintu ruangan kelas, tentunya secara manual menggunakan tenaga manusia.Saat petugas ingin membuka pintu ruangan kelas, petugas harus memasukan kunci dan memutarnya kunci tersebut lalu mendorongnya dan membuka pintu ruangan kelas satu persatu disetiap lantainya.Hal itu cukup merepotkan bagi petugas untuk membuka pintu ruangan kelas disetiap lantainya.

Prosedur Sistem yang dirancang yaitu prosedur perintah dengan bluetooth.Hal yang dapat dilakukan jika petugas dari sistem ini ingin mengendalikan pintu ruangan kelas baik membuka, menutup, mengunci dan membuka kunci.Petugas cukup menyalakan handphone androidnya dan terkoneksi dengan bluetooth lalu membuka aplikasi bluetooth controller lalu menekan tombol keyboard tertentu untuk membuka dan menutup pintu ruangan kelas yang tersambung ke Mikrokontroller ATMega328. Dan juga menggunakan prosedur buka pintu kelas, saat ada instruksi berupa kode tertentu 
yang dikirimkan dari ponsel android melewati bluetooth, mikrokontroller ATMega328 akan memproses instruksi tersebut dan memberikan data pada IC Driver Motor L293D untuk menggerakan Motor Servo yang berfungsi sebagai membuka, menutup, membuka kunci dan mengunci pintu ruangan kelas.

Perangkat lunak dibutuhkan untuk memprogram cara kerja dari mikrokontroller agar sistem dapat bekerja secara otomatis. Gambar 1 menunjukan diagram alir program atau sistem yang digunakan untukmembuka, menutup, mengunci dan membuka kunci pintu ruangan kelas secara otomatis dengan perintah melalui inputan data yang diberikan handphone yang sudah terkoneksi bluetooth melewati aplikasi bluetooth controller dengan format tertentu, baik untuk membuka, menutup, mengunci dan membuka kunci pintu ruangan kelas. Setelah pintu ruangan kelas mengikuti instruksi yang diberikan oleh handphone tersebut dari mikrokontroller maka lampu indikator atau LED akan menyala jika pintu ruangan kelas tertutup berwarna merah dan berwarna biru ketika pintu ruangan kelas terbuka.

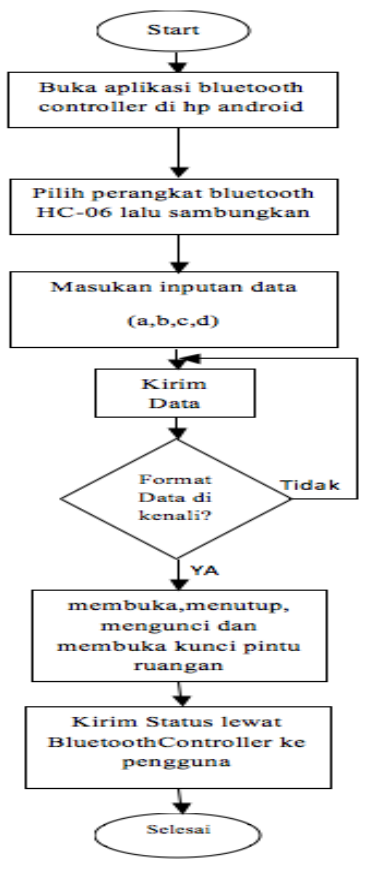

Gambar 1.Diagram alur sistem lock and controlling class room dengan interface android berbasis arduino uno

\section{Rancangan sistem secara keseluruhan}

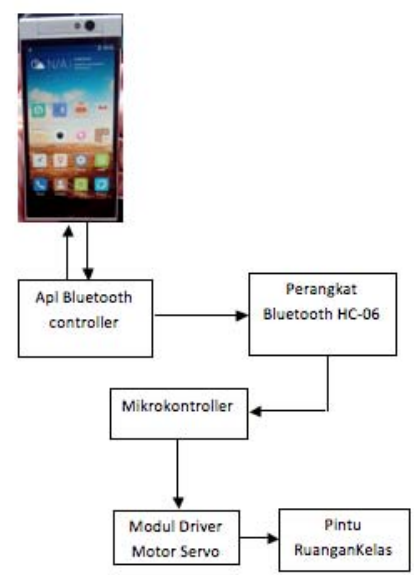

Gambar 2. Diagram Sistem Keseluruhan

Sesuai gambar diatas, ponsel sebagai perangkat untuk mengirim data dari petugas melalui aplikasi bluetooth controller yang sudah terkoneksi dengan perangkat bluetoooth HC-06 dan data nantinya akan diproses oleh mikrokontroller untuk menggerakkan motor servo melalui modul driver motor servo. Setelah mikrokontroller berhasil mengenali perintah dari aplikasi bluetooth controller, maka mikrokontroller akan mengirimkan data ke modul driver motor servo yang selanjutnya akan menjalankan motor servo sebagai penggerak pintu ruangan kelas terbuka, tertutup, mengunci dan membuka kunci.

Agar mempermudah penulis dalam menjelaskan perancangan perangkat keras, maka di gambarkan alur dan cara kerja perangkat keras pada rangkaian diagram blok pada gambar 3 bawah ini: 


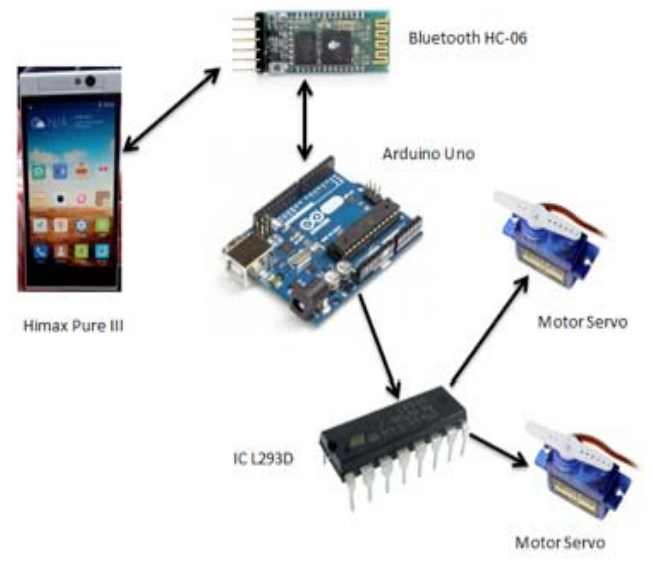

Gambar 3. Diagram Blok

Pada gambar 3 merupakan alur dari diagram blok, yang dimana terdapat konfigurasi seluruh rangkaian yang digunakan. Prinsip dari kerja sistem yang di rancang adalah Smartphone menjadi media untuk memberikan input pada mikrokontroller dan ketika mikrokontroller mendapat inputan dari smartphone, ke dua motor servo maka masing-masing output akan berada pada logika HIGH dan sebaliknya akan mendapat logika LOW.

\section{IMPLEMENTASI}

Mikrokontroller bisa bekerja jika di dalamnya sudah dimasukkan listing program, program yang akan dimasukan kedalam mikrokontroller ATmega328 yaitu program aplikasi yang dibuat dengan aplikasi Arduino 1.0. Untuk melakukan pengisian program menggunakan perangkat keras (Hardware) dan perangkat lunak (Software) Dengan menggunakan arduino sebagai media untuk memasukan program ke dalam mikrokontroller ATmega328, maka program yang ditulis pada Arduino 1.0 dapat langsung dimasukan kedalam mikrokontroller ATmega328. Langkah selanjutnya sebelum listing program dimasukan ke dalam mikrokontroller, yang perlu diperhatikan yaitu jenis board yang akan digunakan pada saat memasukan listing program, proses pemilihan board yang digunakan untuk memasukan listing program dapat dilihat pada gambar 16 sebagai berikut:

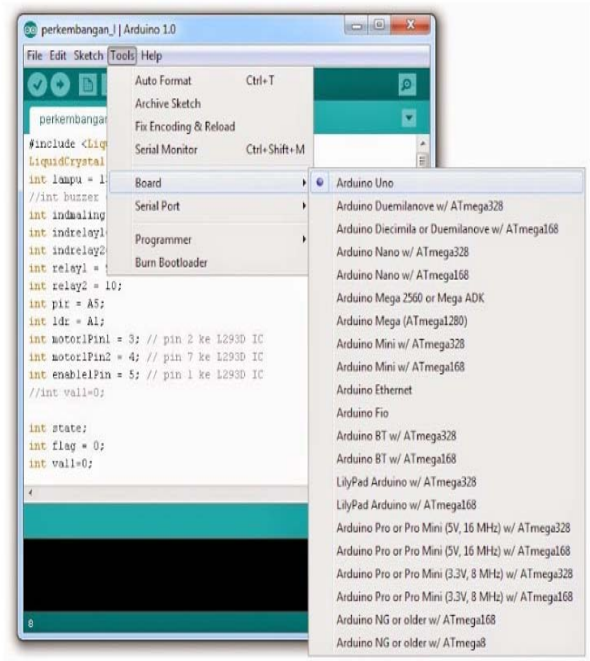

\section{Gambar 4. Pemilihan arduino board dan memasukan listing program}

Setelah jenis board sudah dipilih, langkah selanjutnya adalah memasukan program ke dalam mikrokontroller dengan menggunakan internal clock, arti dari internal clock adalah dengan memanfaatkan board Arduino sebagai board untuk berkomunikasi dengan komputer, dan mikrokontroller yang ada pada arduino board tersebut dilepas, agar IC ATmega328 yang akan digunakan dapat terbaca oleh Arduino board. 


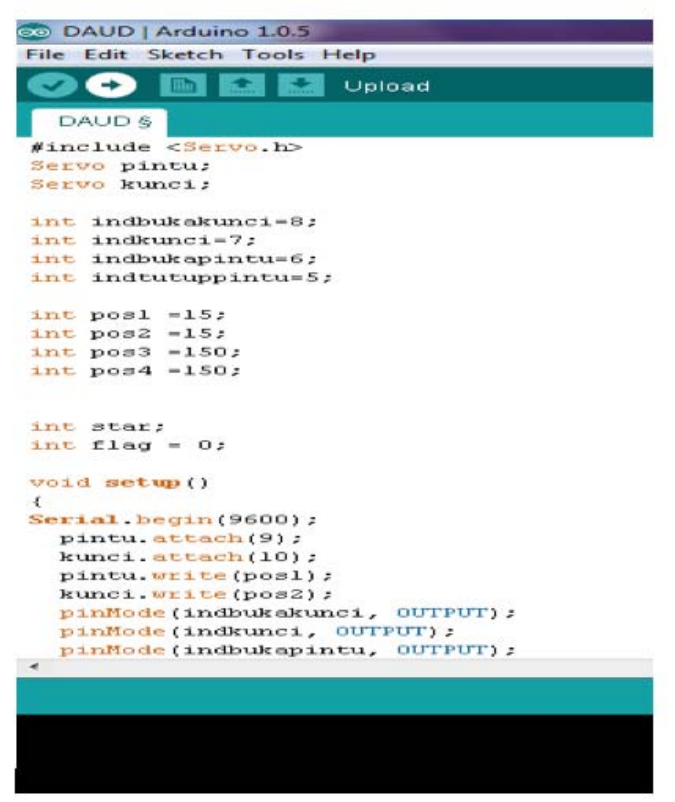

Gambar 5. Mengupload program kedalam mikrokontroller ATMega328

Pada tampilan pemrograman Arduino 1.0 diatas, dilakukan dengan mengklik tombol upload yang ada pada Arduino 1.0, pada saat mengupload listing program secara otomatis akan menampilkan pesan bahwa proses upload program tidak terjadi error atau sukses.

Pada perancangan kali ini memanfaatkan aplikasi bluetooth controller. Program ini bisa didownload free via Play Store.maka Selanjutnya kita buka program bluetooth controller pada Android gadget

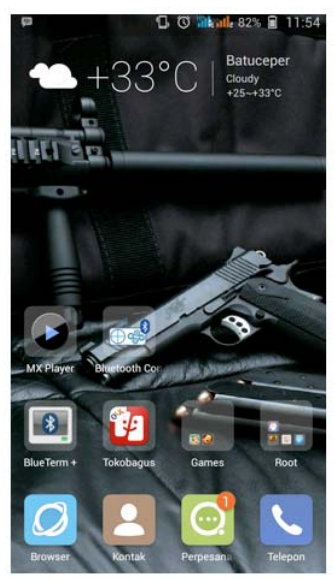

Gambar 6. Ikon Aplikasi Bluetooth Controller pada Android
Lalu Pastikan bluetooth pada smartphone sudah aktif, selanjutnya klik icon BLUETOOTH CONTROLLER, tekan Scan dan pilih 'Connect Device'.

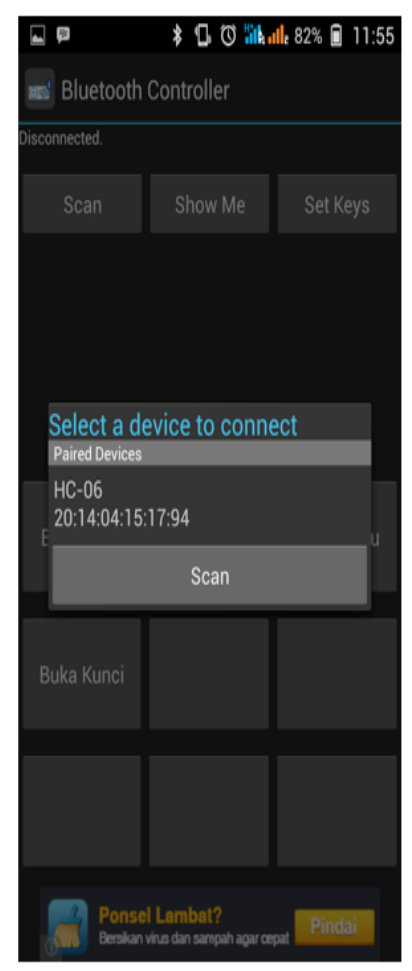

Gambar 7. Koneksi device pada bluetooth controller

Pilih nama device BTSM yang terpasang pada Arduino, selanjutnya LED pada BTSM akan menyala konstan jika proses pairing berhasil dilakukan. Jika BTSM yang terpasang belum pernah pairing dengan BT Master, maka akan ditanyakan PIN CODE, masukkan 4 digit pin code (defaultnya 1234).

Jika sudah terkoneksi selanjutnya masukan perintah pada Android dengan mengetikan karakter huruf :

"a" untuk membuka pintu, "b" untuk menutup pintu, "c" untuk mengunci pintu "d" untuk membuka kunci pintu Dan maka tampilan pada android seperti gambar dibawah ini. 


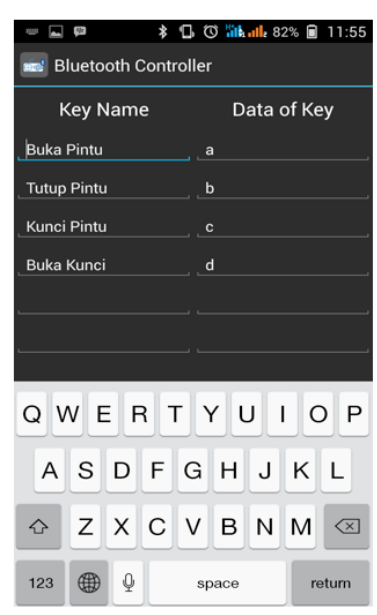

Gambar 8. Tampilan pada smartphone android

Tabel 1. Blackbox Testing

\begin{tabular}{|l|l|l|l|l|}
\hline No & $\begin{array}{l}\text { Pengujia } \\
\text { n }\end{array}$ & $\begin{array}{l}\text { Test } \\
\text { Case }\end{array}$ & $\begin{array}{l}\text { Hasi } \\
\text { l } \\
\text { Yan } \\
\text { g } \\
\text { Diha } \\
\text { rapk } \\
\text { an }\end{array}$ & $\begin{array}{l}\text { Hasil } \\
\text { ujian }\end{array}$ \\
\hline 1 & $\begin{array}{l}\text { Layer } \\
\text { Menu } \\
\text { Awal } \\
\text { yang } \\
\text { tidak } \\
\text { mengakt } \\
\text { ifkan } \\
\text { Bluetoot } \\
h\end{array}$ & $\begin{array}{l}\text { Tidak } \\
\text { terko } \\
\text { neksi } \\
\text { denga } \\
\text { nluet } \\
\text { ooth }\end{array}$ & $\begin{array}{l}\text { Sistem } \\
\text { tidak } \\
\text { akan } \\
\text { Menam } \\
\text { pilkan } \\
\text { menu } \\
\text { utama } \\
\text { pengon } \\
\text { trolan } \\
\text { dan } \\
\text { akan } \\
\text { secara } \\
\text { otomati } \\
\text { s } \\
\text { menga } \\
\text { ktifkan } \\
\text { Bluetoo } \\
\text { th }\end{array}$ & Valid \\
\hline 2 & $\begin{array}{l}\text { Menu } \\
\text { Awal }\end{array}$ & $\begin{array}{l}\text { Terko } \\
\text { neksi } \\
\text { denga }\end{array}$ & $\begin{array}{l}\text { Sistem } \\
\text { akan } \\
\text { langsu }\end{array}$ & Valid \\
\hline
\end{tabular}

\begin{tabular}{|c|c|c|c|c|}
\hline & $\begin{array}{l}\text { yang } \\
\text { terkonek } \\
\text { si } \\
\text { dengan } \\
\text { Bluetoot } \\
\text { h }\end{array}$ & $\begin{array}{l}\text { n } \\
\text { Bluet } \\
\text { ooth }\end{array}$ & $\begin{array}{l}\text { ng } \\
\text { menam } \\
\text { pilkan } \\
\text { menu } \\
\text { utama } \\
\text { pengon } \\
\text { trolan }\end{array}$ & \\
\hline 3 & $\begin{array}{l}\text { Button } \\
\text { Membuk } \\
\text { a Kunci }\end{array}$ & $\begin{array}{l}\text { Click } \\
\text { Butto } \\
\text { n } \\
\text { Mem } \\
\text { buka } \\
\text { Kunci } \\
\text { Pintu }\end{array}$ & $\begin{array}{l}\text { Akan } \\
\text { Mengiris } \\
\text { kan } \\
\text { String } \\
\text { mikroko } \\
\text { troller } \\
\text { untuk } \\
\text { membuk } \\
\text { kunci } \\
\text { pintu } \\
\text { utama }\end{array}$ & Valid \\
\hline 4 & $\begin{array}{l}\text { Button } \\
\text { Mengun } \\
\text { ci Pintu }\end{array}$ & $\begin{array}{l}\text { Click } \\
\text { Butto } \\
\text { n } \\
\text { Meng } \\
\text { unci } \\
\text { Pintu }\end{array}$ & $\begin{array}{l}\text { Akan } \\
\text { Mengir } \\
\text { imkan } \\
\text { String } \\
\text { ke } \\
\text { mikrok } \\
\text { ontroll } \\
\text { er } \\
\text { untuk } \\
\text { mengu } \\
\text { nci } \\
\text { pintu } \\
\text { utama }\end{array}$ & Valid \\
\hline 5 & $\begin{array}{l}\text { Button } \\
\text { Membuk } \\
\text { a Pintu }\end{array}$ & $\begin{array}{l}\text { Click } \\
\text { Butto } \\
\text { n } \\
\text { Mem } \\
\text { buka } \\
\text { Pintu }\end{array}$ & $\begin{array}{l}\text { Akan } \\
\text { Mengir } \\
\text { imkan } \\
\text { String } \\
\text { ke } \\
\text { mikrok } \\
\text { ontroll } \\
\text { er } \\
\text { untuk } \\
\text { membu } \\
\text { ka } \\
\text { pintu } \\
\text { kelas }\end{array}$ & Valid \\
\hline
\end{tabular}




\begin{tabular}{|l|l|l|l|l|}
\hline 6 & Button & Click & Akan & Valid \\
& Menutu & Butto & Mengir & \\
p Pintu & imkan & \\
& & $\begin{array}{l}\text { Menu } \\
\text { tup }\end{array}$ & $\begin{array}{l}\text { String } \\
\text { ke } \\
\text { Pintu }\end{array}$ & \\
& & $\begin{array}{l}\text { mikork } \\
\text { ontroll } \\
\text { er } \\
\text { untuk } \\
\end{array}$ & \\
& & $\begin{array}{l}\text { menutu } \\
\text { p pintu } \\
\text { kelas }\end{array}$ & \\
& & & \\
\end{tabular}

\section{KESIMPULAN}

Dengan demikian dapat disimpulkan, bahwa dengan adanyapintu ruangan kelas sudah terpasang 2 buah motor servo yang terhubung pada arduino uno yang sudah diprogram agar dapat membuka, menutup, mengunci, dan membuka kunci pintu ruangan kelas. Yang menjadikan petugas tidak perlu repot untuk membuka, menutup, mengunci pintu dan membuka kunci pintu ruangan secara manual. Aplikasi bluetooth yang dipakai untuk mengontrol pintu ruangan kelas ini sudah ada di play store dan dapat diunduh secara gratis yang bernama bluetooth controller. Petugas cukup mengatur aplikasi ini sesuai kebutuhan seperti mengunci, membuka kunci, membuka, menutup pintu.

Ketika mikrokontroller yang sudah diprogram tersebut sudah dapat menjalankan tugasnya maka petugas cukup mengkoneksikan bluetooth dismartphone androidnya pada bluetooth HC-06 yang ada pada mikrokontroller tersebut, lalu memasukan password yaitu "1234" dan ketika sudah terkoneksi, maka petugas sudah dapat mengontrol pintu tersebut.

\section{DAFTAR PUSTAKA}

[1] Dhida Restu GM. 2014. Prototype Pengendali Pintu dan Jendela Mobil Menggunakan Smartphone Berbasis
ATMega 328P Di Kelurahan Cibogo. (Laporan Skripsi, STMIK Raharja, Tangerang).

[2] Dwi Agus Diartono. 2009. Teknologi Bluetooth untuk Layananan Internet pada Wireless Local Area Network. Jurnal Teknologi Informasi DINAMIK. Semarang. Vol. XIV, pp. 70-78. (Januari 2009).

[3] Erinofiardi,Nurul Iman Supardi. Redi2012. "Penggunaan PLC Dalam Pengontrolan Temperatur, Simulasi Pada ProtorypeRuangan".Jurnal Mekanikal, Vol.3 No.2-Juli 2012.

[4] Heri Kuswanto.2014. Sistem Proteksi Kendaraan Bermotor menggunakan Android Berbasis Mikrokontroller ATMega328. (Laporan Skripsi, STMIK Raharja, Tangerang).

[5] Imam Sibro Malisi.2013.Prototype Alat Pengendali Gerbang Menggunakan SMS Gateway. (Laporan KKP, STMIK Raharja, Tangerang).

[6] Mulyanto, Agus. 2009. Per.Pancangan Sistem Informasi Perancangan Dan Pengendalian Terhadap Proses Produksi Pada PT. Indofiber Industri.(Laporan Skripsi, STMIK Raharja, Tangerang).

[7] Purnama, Rangsang. 2010. "Mari Mengenal J2ME ".Prestasi Pustaka:Jakarta.

[8] Reza Nusyah Putra.2014. Prototipe Alat Pembersih Toren Otomatis menggunakan SMS gateway pada PT. Cahaya Televisi Indonesia. (Laporan Skripsi, STMIK Raharja, Tangerang).

[9] Roni Fitramadhana.2013.Aplikasi Sistem Keamanan Pada Ruangan Server Dilengkapi Sensor Suhu, Mekanik Pintu Dan Pengenalan Kode Akses Didukung Webcam Berbasiskan Client Server. (Laporan Skripsi, STMIK Raharja, Tangerang).

[10] Syahid. 2012. "Rancang Bangun Robot BerodaBerbasis Android Menggunakan Komunikasi USB”. ISSN : 2252-4908 Vol. 1 No. 2Agustus $2012: 33-42$. 
[11] Simarmata, Janner. 2010. "REKASA PERANGKAT LUNAK". Yogyakarta: C.V ANDI OFFSET. 